Халитова Лариса Рафиковна

кандидат экономических наук, доцент, доцент кафедры экономики и менеджмента Башкирского государственного

аграрного университета

\section{ОЦЕНКА ВЛИЯНИЯ ПОТРЕБЛЕНИЯ ПРОДУКТОВ ПИТАНИЯ НА ПОКУПАТЕЛЬНУЮ СПОСОБНОСТЬ НАСЕЛЕНИЯ (НА ПРИМЕРЕ РЕСПУБЛИКИ БАШКОРТОСТАН)}

\begin{abstract}
Аннотация:
В работе проанализирована покупательная способность заработной платы работников предприятий и организаций Республики Башкортостан (РБ). Использованы общедоступные статистические сведения о потреблении продуктов питания на душу населения РБ, об изменениях номинальной заработной платы и потребительских цен. Рассмотрено влияние факторов на покупательную способность заработной платы. В качестве факторов отобраны двенадцать показателей, которые имеют прямые связи C результативным признаком. В ходе изучения оценки влияния факторов на индекс реальной заработной платы отобраны наиболее значимые, которые являются определяющими в корреляционно-регрессионной модели. На покупательную способность населения влияет потребление следующих продуктов питания: хлеба и хлебобулочных изделий из пиеничной муки, водки обыкновенного качества, цельного молока, сливочного масла, муки пшеничной.
\end{abstract}

Ключевые слова:

заработная плата, покупательная способность, население, индекс, потребление продуктов питания, факторы, Республика Башкортостан.
Khalitova Larisa Rafikovna

PhD in Economics Associate Professor, Economics and Management Department, Bashkir State Agrarian University

\section{ASSESSING THE IMPACT OF FOODSTUFFS CONSUMPTION ON THE CONSUMER PURCHASING POWER (BY A CASE STUDY OF THE REPUBLIC OF BASHKORTOSTAN)}

Summary:

The paper analyzes the purchasing power of company and organization employees' wages in the Republic of Bashkortostan. The research is based on available statistical data on foodstuffs consumption per capita in the Republic of Bashkortostan, changes in nominal wages and consumer prices. The effect of factors on the purchasing power of wages is considered. These factors are represented by twelve indicators which are directly related to their results. Assessing the influence of factors on the real wage index, the author selects the most significant indicators which are crucial in the correlation and regression model. Such foodstuffs as bread and bakery products made from wheat flour, ordinary vodka, whole milk, butter, and wheat flour have the greatest impact on the consumer purchasing power.

Keywords: wages, purchasing power, population, index, food stuffs consumption, factors, Republic of Bashkortostan.

Вопросам изучения уровня заработной платы уделяют много внимания как представители власти, так и ученые-экономисты. Однако снижение уровня жизни населения требует пересмотра многих действующих программ и мер на всех уровнях управления. Одной из главных функций заработной платы является воспроизводственная, которая заключается в восстановлении умственных и физических способностей, затраченных в процессе потребления рабочей силы. Поэтому от ее уровня зависит не только потребление продуктов питания, товаров и услуг, необходимых для поддержания жизни самого работника и членов его семьи, но и эффективность использования денежных средств, направленных на ее выплату в виде фонда заработной платы, предприятиями и организациями в сравнении с ростом производительности труда.

Данная тема исследования актуальна. Проблема заключается в том, что реальная заработная плата в последние годы снижается. Это отражается и на покупательной способности, в том числе на потреблении продуктов питания, для которого характерна тенденция в сторону уменьшения в связи с постоянным повышением цен. В результате наблюдаются негативные тенденции: ухудшение здоровья населения, снижение производительности труда, сокращение продолжительности жизни населения и др. Так, в настоящее время в структуре доходов населения Республики Башкортостан (РБ) на долю заработной платы приходится 28 \% (2015 г.). Она является основной формой дохода большинства работников наемного труда, которые составляют в структуре занятого населения, по некоторым оценкам, более 90 \%. Доходы от предпринимательской деятельности и собственности получает довольно ограниченный контингент населения. По мнению Н.А. Волгина, на показатели уровня жизни в стране и регионе эти статьи доходов влияют тем, что повышают статистическую величину среднедушевого денежного дохода [1, с. 46]. 
В связи с вышеизложенным необходимо периодически проводить мониторинг потребления продуктов питания населением и реальной заработной платы во избежание отрицательных последствий в социально-экономической жизни региона. Это позволит определить допустимый (приемлемый) уровень покупательной способности населения, которого следует придерживаться.

Цель статьи - проанализировать потребление основных продуктов питания на одного человека в зависимости от уровня средней реальной заработной платы работников предприятий и организаций в Республике Башкортостан.

Предметом исследования является покупательная способность реальной заработной платы, поскольку ее размер определяет набор потребления продуктов питания, товаров и услуг. Объектом исследования выбрана Республика Башкортостан.

Информационной базой явились данные о потреблении продуктов питания на душу населения в РБ, индексы номинальной и потребительских цен, приведенных в официально опубликованных статистических сборниках по региону за 2003-2015 гг. [2].

В процессе исследования использовались следующие научные методы: табличный, относительных величин, индексный, корреляционно-регрессионный анализ.

Л.И. Накамура утверждает, что в зависимости от условий хозяйствования при анализе социально-экономического процесса необходимо применять такие инструменты, которые будут иметь практическую значимость [3].

По мнению автора, для исследования покупательной способности заработной платы на основе потребления продуктов питания целесообразно использовать индексы динамики, которые характеризуют изменение сложного явления, состоящего из элементов, непосредственно несоизмеримых в натуральном выражении. На основе имеющихся индексов реальной заработной платы работников организаций и предприятий РБ и индексов потребления основных продуктов питания на душу населения региона были определены прямые и обратные связи между данными явлениями. Это позволило провести оценку отобранных фракторов по характеру связей с их результативным показателем.

Были рассмотрены следующие фракторы:

$\mathrm{X}_{1}$ - рост потребления говядины, доли;

$\mathrm{X}_{2}$ - рост потребления сливочного масла, доли;

$\mathrm{X}_{3}$ - рост потребления подсолнечного масла, доли;

$\mathrm{X}_{4}$ - рост потребления цельного молока, доли;

$\mathrm{X}_{5}$ - рост потребления яиц, доли;

$\mathrm{X}_{6}$ - рост потребления сахарного песка, доли;

$\mathrm{X}_{7}$ - рост потребления муки пшеничной, доли;

$\mathrm{X}_{8}$ - рост потребления хлеба и хлебобулочных изделий из пшеничной муки, доли;

$\mathrm{X}_{9}$ - рост потребления риса, доли;

$\mathrm{X}_{10}$ - рост потребления макаронных изделий, доли;

$\mathrm{X}_{11}$ - рост потребления картофеля, доли;

$\mathrm{X}_{12}$ - рост потребления водки обыкновенного качества, доли.

C помощью «Анализа данных» программы MS Excel определены коэффициенты корреляции, показывающие связь изучаемых факторов с реальной заработной платой. Полученная матрица коэффрициентов корреляции представлена в таблице 1.

Таблица 1 - Матрица коэфффициентов корреляции

\begin{tabular}{|c|c|c|c|c|c|c|c|c|c|c|c|c|c|}
\hline & $\mathrm{y}$ & $\mathrm{X}_{1}$ & $\mathrm{X}_{2}$ & $\mathrm{X}_{3}$ & $\mathrm{X}_{4}$ & $\mathrm{X}_{5}$ & $\mathrm{X}_{6}$ & $\mathrm{X}_{7}$ & $\mathrm{X}_{8}$ & $\mathrm{X}_{9}$ & $\mathrm{X}_{10}$ & $\mathrm{X}_{11}$ & $\mathrm{X}_{12}$ \\
\hline $\mathrm{y}$ & 1,00 & & & & & & & & & & & & \\
\hline $\mathrm{X}_{1}$ & 0,62 & 1,00 & & & & & & & & & & & \\
\hline $\mathrm{X}_{2}$ & 0,39 & 0,25 & 1,00 & & & & & & & & & & \\
\hline $\mathrm{X}_{3}$ & 0,19 & 0,28 & 0,48 & 1,00 & & & & & & & & & \\
\hline $\mathrm{X}_{4}$ & 0,47 & 0,32 & 0,93 & 0,60 & 1,00 & & & & & & & & \\
\hline $\mathrm{X}_{5}$ & 0,35 & $-0,04$ & 0,54 & 0,63 & 0,54 & 1,00 & & & & & & & \\
\hline $\mathrm{X}_{6}$ & 0,67 & 0,63 & 0,53 & 0,07 & 0,51 & 0,01 & 1,00 & & & & & & \\
\hline $\mathrm{X}_{7}$ & 0,31 & $-0,06$ & 0,32 & 0,57 & 0,49 & 0,77 & 0,11 & 1,00 & & & & & \\
\hline $\mathrm{X}_{8}$ & 0,54 & 0,21 & 0,46 & 0,65 & 0,65 & 0,77 & 0,28 & 0,94 & 1,00 & & & & \\
\hline $\mathrm{X}_{9}$ & 0,35 & $-0,04$ & 0,20 & 0,44 & 0,33 & 0,56 & 0,19 & 0,65 & 0,62 & 1,00 & & & \\
\hline $\mathrm{X}_{10}$ & 0,47 & 0,20 & 0,42 & 0,84 & 0,63 & 0,79 & 0,12 & 0,84 & 0,91 & 0,74 & 1,00 & & \\
\hline $\mathrm{X}_{11}$ & 0,00 & 0,15 & 0,60 & 0,41 & 0,60 & 0,00 & 0,40 & 0,06 & 0,08 & 0,12 & 0,17 & 1,00 & \\
\hline $\mathrm{X}_{12}$ & 0,51 & 0,14 & 0,65 & 0,12 & 0,57 & 0,60 & 0,35 & 0,39 & 0,42 & 0,18 & 0,30 & 0,25 & 1,00 \\
\hline
\end{tabular}


Используя шкалу Чеддока, охарактеризуем связи между результативным (Y) и факторными признаками $\left(\mathrm{X}_{1}, \mathrm{X}_{2}, \mathrm{X}_{3}, \mathrm{X}_{4}, \mathrm{X}_{5}, \mathrm{X}_{6}, \mathrm{X}_{7}, \mathrm{X}_{8}, \mathrm{X}_{9}, \mathrm{X}_{10}, \mathrm{X}_{11}, \mathrm{X}_{12}\right)$. Так, по значениям второго столбца видно, что реальная заработная плата имеет прямую связь с уровнями потребления говядины, сливочного масла, цельного молока, яиц, сахарного песка, муки пшеничной, хлеба и хлебобулочных изделий, риса, макаронных изделий и водки обыкновенного качества. Связь реальной заработной платы с потреблением картофеля и подсолнечного масла практически отсутствует. Это обусловлено тем, что картофель для нужд семьи обычно выращивают на приусадебных участках или же в необходимых количествах для потребления приобретают на осенних и зимних ярмарках в городах РБ. Такие мероприятия организуют органы местной власти, что позволяет стимулировать развитие крестьянско-фрермерских и личных подсобных хозяйств, которые реализуют излишки произведенной сельскохозяйственной продукции (овощи, картофель, мясо сельскохозяйственных животных и птицы, мед и др.).

Далее проведена оценка совокупности изучаемых признаков на однородность с применением коэффиццента вариации. Данный коэффрициент представлен в таблице 2.

Таблица 2 - Коэффициенты вариации рассматриваемых признаков

\begin{tabular}{|l|c|c|}
\hline \multicolumn{1}{|c|}{ Признак } & $\begin{array}{c}\text { Значение } \\
\text { коэффициента }\end{array}$ & Интерпретация значения \\
\hline Индекс реальной заработной платы, доли & 7,56 & совокупность однородная \\
\hline Рост потребления говядины, доли & 10,61 & совокупность однородная \\
\hline Рост потребления сливочного масла, доли & 11,08 & совокупность однородная \\
\hline Рост потребления подсолнечного масла, доли & 18,98 & совокупность однородная \\
\hline Рост потребления цельного молока, доли & 8,96 & совокупность однородная \\
\hline Рост потребления яиц, доли & 12,63 & совокупность однородная \\
\hline Рост потребления сахарного песка, доли & 20,87 & совокупность однородная \\
\hline Рост потребления муки пшеничной, доли & 17,40 & совокупность однородная \\
\hline $\begin{array}{l}\text { Рост потребления хлеба и хлебобулочных изделий } \\
\text { из пшеничной муки, доли }\end{array}$ & 10,37 & совокупность однородная \\
\hline Рост потребления риса, доли & 13,15 & совокупность однородная \\
\hline Рост потребления макаронных изделий, доли & 11,19 & совокупность однородная \\
\hline Рост потребления картофеля, доли & 31,15 & совокупность неоднородная \\
\hline Рост потребления водки обыкновенного качества, доли & 11,66 & совокупность однородная \\
\hline
\end{tabular}

Как видим, анализируемые факторы (кроме потребления картофеля) однородны, так как коэффициент вариации во всех случаях меньше 30-33 \%. Следовательно, на их основе можно построить корреляционно-регрессионную модель реальной заработной платы и сделать ее проверку на значимость.

После построения нескольких корреляционно-регрессионных моделей были проведены оценки по определенным показателям: множественному коэффицциенту корреляции, $t$-критерию Стьюдента, F-критерию Фишера.

В результате исследования была выбрана модель, выраженная следующим математическим уравнением:

$$
\mathrm{y}=-0,38 \mathrm{X}_{2}+0,14 \mathrm{X}_{4}-0,69 \mathrm{X}_{7}+1,46 \mathrm{X}_{8}+0,34 \mathrm{X}_{12}+0,16 \text {, }
$$

где $a_{0}=0,16-$ свободный член уравнения регрессии, оценке взаимосвязи не подлежит;

$a_{2}=-0,38$ - коэффициент чистой регрессии при первом фракторе показывает, что при увеличении уровня потребления сливочного масла на 1 \% может произойти уменьшение индекса реальной заработной платы на 0,38 \%, при условии что остальные фракторы не изменятся;

$a_{4}=0,14-$ коэффициент чистой регрессии при втором фракторе свидетельствует о том, что при повышении потребления цельного молока на 1 \% индекс реальной заработной платы должен увеличиться на 0,14 \%, при условии что остальные фракторы будут прежними;

$a_{7}=-0,69-$ коэфффициент чистой регрессии при третьем фракторе показывает, что при увеличении потребления муки пшеничной на 1 \% может произойти снижение индекса реальной заработной платы на 0,69 \%, при условии что остальные фракторы будут прежними;

$a_{8}=1,46$ - коэффициент чистой регрессии при третьем фракторе показывает, что при росте потребления хлеба и хлебобулочных изделий из пшеничной муки на 1 \% индекс реальной заработной платы должен повыситься на 1,46 \%, при условии что остальные фракторы будут прежними;

$a_{12}=0,34-$ коэффициент чистой регрессии при третьем факторе показывает, что при повышении потребления водки обыкновенного качества на 1 \% индекс реальной заработной платы должен повыситься на 0,34, при условии что остальные факторы будут прежними.

Далее рассмотрим точность построенной модели, исходя из показателей таблицы 3. 
Таблица 3 - Показатели модели зависимости воспроизводства рабочей силы РБ от совокупности факторов

\begin{tabular}{|l|c|}
\hline \multicolumn{1}{|c|}{ Показатель } & 3начение \\
\hline Множественный коэффициент корреляции $(R)$ & 0,899 \\
\hline Коэффициент детерминации $\left(R^{2}\right)$ & 0,808 \\
\hline Стандартная ошибка & 0,038 \\
\hline Наблюдения & 12 \\
\hline
\end{tabular}

Множественный коэффициент корреляции равен 0,899. Это означает, что полученная модель пригодна к применению. Вариация индекса реальной заработной платы на 80,8 \% объясняется анализируемыми факторами.

Показатели множественной регрессии приведены в таблице 4.

\section{Таблица 4 - Показатели множественной регрессии}

\begin{tabular}{|l|c|c|c|c|}
\hline \multicolumn{1}{|c|}{ Показатель } & $\begin{array}{c}\text { Коэффициент } \\
\text { регрессии }\end{array}$ & $\begin{array}{c}\text { Стандартная } \\
\text { ошибка }\end{array}$ & t-статистика & Р-значение \\
\hline Индекс реальной заработной платы, доли & 0,16 & 0,176 & 0,921 & 0,392 \\
\hline Рост потребления сливочного масла, доли & $-0,38$ & 0,157 & $-2,428$ & 0,051 \\
\hline Рост потребления цельного молока, доли & 0,14 & 0,064 & 2,234 & 0,067 \\
\hline $\begin{array}{l}\text { Рост потребления хлеба и хлебобулочных } \\
\text { изделий из пшеничной муки, доли }\end{array}$ & $-0,69$ & 0,218 & $-3,171$ & 0,019 \\
\hline Рост потребления муки пшеничной, доли & 1,46 & 0,393 & 3,706 & 0,010 \\
\hline $\begin{array}{l}\text { Рост потребления водки обыкновенного } \\
\text { качества, доли }\end{array}$ & 0,34 & 0,132 & 2,590 & 0,041 \\
\hline
\end{tabular}

Табличное значение $t$-критерия при уровне значимости $5 \%$ и степенях свободы (12 $-5-1=6)$ составляет 2,45; расчетные значения $t a_{2}=-2,428 ; t a_{4}=2,234 ; t a_{7}=-3,171 ; t a_{8}=3,706 ; t a_{12}=$ 2,590 .

Так как $t a_{7}>t_{\text {табл }}, t a_{8}>t_{\text {табл }}, t a_{12}>t_{\text {табл }}$, то можно утверждать, что эти коэфрфициенты существенны и отобранные факторы необходимы для модели. Для второго и четвертого факторов разницы между рассчитанными коэфрфициентами и табличным значением небольшие, это соответственно 0,0188 и 0,2128. Следовательно, второй и четвертый фракторы можно включить в модель.

Адекватность регрессионной модели проанализирована с использованием $F$-критерия Фишера. Табличное значение $F$-критерия Фишера при уровне значимости $5 \%$ и степенях свободы $\left(k_{1}=\right.$ $5, k_{2}=n-m-1=6$ ) составляет 4,39. Расчетное значение равно 8,393, что больше табличного.

Так как $F_{\text {табл }}<F_{\text {факт }}$ и показатель значимости меньше заданного уровня $\alpha=0,05$, то значение индекса детерминации признается типичным и модель связи между признаками $X_{2}, X_{4}, X_{7}, X_{8}$, $X_{12}$ и $Y$ применима для прогнозирования индекса реальной заработной платы работников предприятий и организаций в Республике Башкортостан.

Далее рассмотрен вклад каждого рассматриваемого фрактора в изменение индекса реальной заработной платы с помощью $\beta$-коэфрфициента. Расчеты $\beta$-коэффициентов выглядят следующим образом:

$$
\begin{gathered}
\beta_{2}=\frac{-0,38 \cdot 0,115}{0,080}=-0,546 ; \beta_{4}=\frac{0,14 \cdot 0,229}{0,080}=0,401 ; \beta_{7}=\frac{-0,69 \cdot 0,186}{0,080}=-1,604 ; \\
\beta_{8}=\frac{1,46 \cdot 0,108}{0,080}=1,971 ; \beta_{12}=\frac{0,34 \cdot 0,121}{0,080}=0,514 .
\end{gathered}
$$

Сопоставление -коэффициентов выявило, что наиболее сильное влияние на варьирование индекса реальной заработной платы оказывает в первую очередь потребление хлеба и хлебобулочных изделий из пшеничной муки, вторым по силе воздействия является потребление водки обыкновенного качества, третьим - потребление цельного молока, четвертым - потребление сливочного масла, пятым - потребление муки пшеничной.

Кроме того, рассчитан «чистый» вклад потребления каждого продукта питания в изменение результативного признака. Из общего объема вариации результативного признака первый фактор (из вышерассмотренных) объясняет 106,4 \%, второй - 26,3, третий - 18,9, четвертый - $(-21,2)$, пятый - $(-49,6 \%)$, а в целом 80,8 \% вариации индекса реальной заработной платы связано с анализируемыми фракторами

$$
\begin{gathered}
d_{2}=r_{y x 2} \cdot \beta_{2}=0,39 \cdot(-0,544)=-0,212 ; d_{4}=r_{y x 4} \cdot \beta_{4}=0,47 \cdot 0,401=0,189 ; \\
d_{7}=r_{y x 7} \cdot \beta_{7}=0,31 \cdot(-1,601)=-0,496 ; d_{8}=r_{y x 8} \cdot \beta_{8}=0,54 \cdot 1,971=-1,064 ; \\
d_{12}=r_{y x 12} \cdot \beta_{12}=0,51 \cdot 0,516=0,263 ; \\
D=d_{2}+d_{4}+d_{7}+d_{8}+d_{12}=-0,212+0,189-0,496+1,064+0,263=0,808 .
\end{gathered}
$$


На основе полученной корреляционно-регрессионной модели были определены альтернативные уровни реальной заработной платы (таблица 5).

Таблица 5 - Альтернативные варианты индекса реальной заработной платы работников предприятий и организаций РБ

\begin{tabular}{|l|c|c|}
\hline \multirow{2}{*}{ Вариант индекса реальной заработной платы } & \multicolumn{2}{|c|}{ Индекс реальной заработной платы } \\
\cline { 2 - 3 } & \% & Изменение, п.п. \\
\hline фактический & 90,9 & - \\
\hline теоретический & 94,4 & 3,5 \\
\hline оптимистический & 119,4 & 28,5 \\
\hline пессимистический & 96,5 & 5,6 \\
\hline усредненный & 105,7 & 14,8 \\
\hline
\end{tabular}

Рассчитанные варианты индекса реальной заработной платы дают возможность сравнить их с фрактическим уровнем и делать на практике объективную оценку сложившегося состояния в РБ.

В данном случае наилучший уровень реальной заработной платы соответствует его оптимистическому значению 119,4 \%, наихудший уровень - теоретическому варианту 94,4 \%, при фактическом состоянии развития - 90,9 \%, при среднем развитии данного процесса - 105,7 \%.

Таким образом, для повышения покупательной способности населения целесообразно проводить мероприятия, направленные на организацию продуктовых и овощных ярмарок для сельскохозяйственных товаропроизводителей, регулирование цен на основные продукты питания, повышение воспроизводственной роли оплаты труда за счет индексации ее в соответствии с темпами роста инфляции и доведения МРОТ до уровня прожиточного минимума.

Достоверность приведенных результатов подтверждается тем, что использованы фактические данные Федеральной службы государственной статистики по Республике Башкортостан, полученные результаты корреляционно-регрессионного анализа соответствуют оценочным критериям.

Научную новизну работы составляет построенная экономико-математическая модель потребления продуктов питания населением РБ, позволяющая установить реально существующую покупательную способность заработной платы.

Теоретическая значимость проведенных исследований заключается в том, что анализ покупательной способности населения РБ произведен в динамике за тринадцать лет. Кроме того, дополнительно рассмотрены индексы реальной заработной платы во взаимосвязи с индексами потребления продуктов питания, чего ранее никем не делалось.

Предложенная рабочая гипотеза о возможности использования выявленной корреляционно-регрессионной модели реальной заработной платы верна, поскольку применима для прогнозирования уровня социально-экономического развития в РБ.

В процессе исследования покупательной способности заработной платы было рассмотрено потребление следующих основных продуктов питания: говядины, сливочного масла, подсолнечного масла, цельного молока, яиц, сахарного песка, муки пшеничной, хлеба и хлебобулочных изделий из пшеничной муки, риса, макаронных изделий, картофеля, водки обыкновенного качества.

Корреляционный анализ показал, что наиболее значимое влияние на покупательную способность населения РБ оказывает потребление хлеба и хлебобулочных изделий из пшеничной муки, водки обыкновенного качества, цельного молока, сливочного масла, муки пшеничной. Потребление других продуктов питания в модели оказалось несущественным, поэтому в дальнейшем они были исключены.

Регрессионный анализ в динамике с 2003 по 2015 г. позволил выявить покупательную способность населения по потреблению продуктов питания. На вариацию 80,8 \% индекса реальной заработной платы наиболее сильное влияние (106,4 \%) оказывает потребление хлеба и хлебобулочных изделий. Воздействие потребления водки обыкновенного качества и цельного молока составляет соответственно 26,3 и 18,9 \%. Потребление сливочного масла и муки пшеничной снижает изменение покупательной способности населения на 21,2 и 49,6 \% соответственно.

Исследование показало, что наилучший уровень реальной заработной платы соответствует его оптимистическому значению 119,4 \%, наихудший уровень - теоретическому варианту 94,4 \%, при фактическом состоянии развития - 90,9 \%, при среднем развитии данного процесса - 105,7 \%. Потребление продуктов питания по данным вариантам представлено в сводной таблице 6.

В таблице 6 не приведены сведения о потреблении продуктов питания по теоретическому варианту, поскольку модель включает только потребление пяти продуктов питания. На варианты индекса реальной заработной платы существенное влияние оказывают цены на продукты питания. В связи с этим в рассмотренных вариантах приведенная потребительская корзина несколько отличается. Так, по оптимистическому варианту потребление населением РБ продуктов питания имеет высокие значения по следующим видам: говядине, сливочному маслу, цельному молоку, сахарному песку, хлебу и хлебобулочным изделиям. 
Таблица 6 - Потребление продуктов питания на душу населения РБ

\begin{tabular}{|l|c|c|c|}
\hline \multirow{2}{*}{ Продукты питания } & \multicolumn{2}{|c|}{ Вариант индекса реальной заработной платы } \\
\cline { 2 - 4 } & $\begin{array}{c}\text { фактический } \\
\mathbf{( 9 0 , 9} \%)\end{array}$ & $\begin{array}{c}\text { усредненный } \\
\mathbf{( 1 0 5 , 7 \% )}\end{array}$ & $\begin{array}{c}\text { оптимистический } \\
\mathbf{( 1 1 9 , 4} \mathbf{\%})\end{array}$ \\
\hline Говядина, кг & 90,4 & 88,4 & 91 \\
\hline Масло сливочное, кг & 84,1 & 91,2 & 258,5 \\
\hline Масло подсолнечное, кг & 296 & 255,2 & 774,4 \\
\hline Цельное молоко, л & 617,2 & 651,8 & 4261 \\
\hline Яйца, шт. & 5311 & 4800 & 543,6 \\
\hline Сахар-песок, кг & 541,2 & 523,4 & 835,5 \\
\hline Мука пшеничная, кг & 915 & 842,3 & 529,7 \\
\hline $\begin{array}{l}\text { Хлеб и хлебобулочные изделия } \\
\text { из пшеничной муки, кг }\end{array}$ & 527,4 & 502,5 & 431,3 \\
\hline Рис, кг & 482,4 & 458,8 & 479,2 \\
\hline Макаронные изделия, кг & 581,2 & 486,6 & 1074,6 \\
\hline Картофель, кг & 1126,1 & 949,1 & 68,3 \\
\hline Водка обыкновенного качества, л & 57,4 & 65,3 & \\
\hline
\end{tabular}

Таким образом, выявленная зависимость покупательной способности заработной платы от потребления основных продуктов питания позволила сделать реальную оценку уровня социально-экономического развития РБ.

\section{Ссылки:}

1. Волгин Н.А., Будаев Т.Б. Оплата труда и проблемы ее регулирования. М., 2006. 200 с.

2. Статистический сборник. Республика Башкортостан в цифрах : стат. сб. : в 2 ч. Ч. 2. Уфра, 2016. 240 с.

3. Nakamura L.I. Economics and the New Economy: The Invisible Hand Meets Creative Destruction // Business Review. 2000. July/August. P. 15-30.

\section{References:}

Nakamura, LI 2000, 'Economics and the New Economy: The Invisible Hand Meets Creative Destruction', Business Review, July/August, pp. 15-30.

Statistical Yearbook of the Republic of Bashkortostan 2016: a statistical digest 2016, in 2 parts, part 2, Ufa, 240 p., (in Russian)

Volgin, NA \& Budaev, TB 2006, Wage and the problems of its regulation, Moscow, 200 p., (in Russian). 